RESENHA: MÃE, Valter Hugo. O filho de mil homens. São Paulo: Cosac Naify, 2012.

\title{
O FILHO DE MIL HOMENS E A CONSTRUÇÃO DA FAMÍLIA MODERNA
}

Fagner Costa e Silva ${ }^{1}$

\section{O autor}

Valter Hugo Mãe nasceu na cidade de Saurino em Angola, mudou-se ainda criança para Portugal, onde se formou em Direito e pós graduou-se em Literatura Portuguesa. Sua produção engloba poesias, romances e literatura infanto-juvenil. Mãe também é artista plástico e cantor da banda de rock $O$ governo. Foi editor, publicando em Portugal livros de escritores brasileiros como: Chico Buarque, Adriana Calcanhoto, Caetano Veloso e Ferreira Gullar.

Sua produção narrativa recebeu - e vem recebendo - análises elogiosas pelos críticos e por seus colegas do universo literário. Dentre estas, destaca-se como mais notável, a do escritor Jose Saramago que, ao entregar ao angolano o prêmio que leva seu nome, disse: "A experiência da leitura de Hugo Mãe é como assistir a um novo parto da língua portuguesa".

Hugo Mãe, em sua literatura, procurar utilizar a língua portuguesa e suas possibilidades para instigar no leitor reflexões filosóficas, como podemos ver no livro $O$ filho de mil homens. É breve nas descrições dos personagens, mostrando-se como discípulo/dissidente da escola literária portuguesa, em que Eça de Queiroz com suas minúcias descrevia seus cenários e seus personagens. O estilo de Hugo Mãe aproxima-se da literatura de Miguel Torga, com sua precisão de sentido na construção do texto.

As aparentes superficialidades nas descrições de seus personagens não significam uma ausência de profundidade, pelo contrário, Hugo Mãe sabe "engatar" seus personagens e suas descrições. É uma escrita ao mesmo tempo simples e profunda, assemelhando-se à descrição que o crítico James Wood faz de um livro de Ford Madox sobre Josef Conrad, alertando aos riscos que os escritores novatos geralmente cometem ao descrever suas cenas

${ }^{1}$ Mestrando em Crítica cultural (UNEB); Especialista em Estudos literários (UEFS) e Ensino de Filosofia (UFBA); Professor da Faculdade Euclides da Cunha (FAEC), E-mail: bitencourt65@hotmail.com

Pontos de Interrogaçầo, v. 7, n. 1, jan.-jun., p. 193-198, 2017. 
assemelhando-as a fotografias. Para Wood, "É importante encarar o leitor com a capacidade de decifração das palavras", e isso Mãe consegue fazer.

A aparente fragilidade e descrição caricatural dos personagens no romance $\mathrm{O}$ filho de mil homens, é compreendida no desenrolar da trama; ele tenta mostrar a visão que o senso comum tem sobre estes homens e mulheres, é a pequena comunidade, com seus preconceitos e julgamentos, influenciando o narrador nas descrições. No entanto, a superficialidade deste diagnóstico vai sendo quebrada no desenvolver da história e dará lugar a reflexões exploratórias da perspectiva do lugar dos excluídos em uma vila que poderia ser em qualquer parte do mundo. Mãe consegue mostrar a profundidade existência das dores dos moradores destes lugares.

\section{O romance}

O livro O filho de mil homens (2012) é dividido em vinte capítulos, os quais contam histórias variadas que vão se entrelaçando e poderiam ser lidas separadamente como contos, já que Hugo Mãe optou (até a metade do livro) por narrar em cada capitulo a história de um embrião de personagens, com a criação de protagonistas nucleares, que possuem os sofrimentos e a exclusão social como fio integrador entre todos.

Estes protagonistas nucleares ou personagens mais destacados da obra são, em sua grande maioria, como aponta o narrador, "aberrações sociais". A vila os exclui, e esta exclusão será o primeiro passo para a integração entre eles. Alguns personagens que merecem destaque são: A Anã, mãe biológica de outro personagem proeminente, o Camilo. Sua história chama a atenção pela comiseração que os outros tinham de sua vida e pela transformação deste sentimento em ira após a revelação de seus casos amorosos. A personagem tem um fim trágico, seu corpo se desfragmenta no parto, e esta é uma das cenas mais viscerais da obra: foi excluída pelos outros, por, além de sua estatura, querer amar e ser amada como qualquer outro ser humano. "Que ridícula soava a ideia de uma triste anã querer amar se o amor era um sentimento raro já para as pessoas normais. Para as pessoas" (MÃE, 2012, p. 25). 
RESENHA: MẪE, Valter Hugo. 0 filho de mil homens. Săo Paulo: Cosac Naify, 2012. 0 FILHO DE MIL HOMENS E A CONSTRUÇÂOO DA FAMILIA MODERNA

O narrador julga a Anã como uma anomalia social, como se pode perceber na frase final do trecho transcrito, em que a exclui do estatuto do ser humano. Trata-se de uma "aberração", palavra que será usada para descrever muitos personagens no romance, como, por exemplo, O Antônio.

O Antônio ou como a vila o chama "O homem maricas", tem em seu núcleo familiar além de sua mãe "a Matilde", Rosinha (a empregada), a Rapariga (filha da empregada) e o Gemúndio (viúvo que se casa com Rosinha). Neste cenário, a problematização das reflexões maiores giram em torno da homossexualidade de Antônio, com poucas folhas do romance dedicado ao casamento arranjado entre a Rosinha e o Gemúndio. Destas cenas, destaca-se a inclusão de um elemento fantástico, a galinha gigante, a qual o narrador utiliza para metaforizar o diferente, já que a ave era a maior entre todas no galinheiro, foi sacrificada por Rosinha, levando o Gemúndio a crer que ela sofreria as consequências do "assassinado de um bicho sagrado", por ironia, Rosinha morre ao comer a carne do animal.

A discussão sobre a homossexualidade de Antônio é uma discussão que percorre boa parte do núcleo e do romance em si, na medida em que deixa claro o quanto sua mãe sofre as consequências de carregar "o fardo de ter um filho maricas" diante de uma comunidade que espera a heteronormatividade dos seus homens. O desamor por eles mesmos é a condição inicial destes personagens, os quais sempre tecem profundas reflexões sobre o que é felicidade e, inicialmente, não acreditam que esta seja possível para eles. Por um lado, Antônio sempre carregava em seu peito a dor de desapontar a mãe que, por sua vez, dividia-se entre o amor que deveria devotar ao filho e a vergonha de tê-lo: "A Matilde, com o coração pequeno e a cabeça confusa a encher-se de ódio, achava que se o filho lhe morresse a vida estaria normal, por que ser mãe fora uma ilusão". (MÃE, 2012, p. 87).

Outro núcleo familiar é o da Isaura, composto por seu pai e sua mãe, personagens, como outros no romance, que não possuem nomes próprios, suas condições estão pautadas nas representações coletivas que denotam suas funções sociais. Nesta família, o drama é ter uma filha "desvirginada", a qual cedeu "às tentações do pecado" antes do casamento. A paranoia dos pais levou a filha a perder o amor próprio, desgostar-se da vida e a odiar-se. Casa-se 
com o Antônio, como um meio convencional para corrigir as "falhas" de ambos perante a sua comunidade. O matrimônio foi fracassado, a amizade entre eles se constrói com muita força.

Todos estes núcleos serão desfragmentados, seus integrantes não conseguem viver com seus respectivos "fardos", consideravam que, para serem felizes, seria preciso cumprir com os regulamentos sociais da vila; eram vítimas daquilo que consideravam certo. O rumo da vida de boa parte destes personagens se modificará quando um outro cruzar seus caminhos, O Crisóstomo, “ Aos quarenta anos, o Crisóstomo mudou o mundo. ”(MÃE, 2012, p. 184).

O Crisóstomo, que chega aos quarenta anos e carrega a dor de não ter filhos "Estava sozinho, os seus amores haviam falhado e sentia que tudo Ihe faltava pela metade" (MÃE, 2012, p.11). Ssua sensação de vazio, que transformava as "coisas em metade", fez com que criasse um boneco para conversar e toma-lo como sua cria, porém a esperança de encontrar um filho feito de carne e osso não o abandonou "imaginava crianças sozinhas a sua espera"(MÃE, 2012.p.11). Encontra o Camilo, um órfão, e o adota como pai. A partir deste núcleo, pai e filho, felizes, mas incompletos, procuram respectivamente uma esposa e uma mãe.

O Crisóstomo é o elemento integrador do romance, sua busca por um filho levará a encontrar uma família, uma família fraternal, concebível nas circunstancias contemporâneas. O leitor pode perceber que esta conjuntura familiar não seria estruturada em outros tempos, as ligações sanguíneas não interessam nas páginas da obra, a união das "aberrações" é mais forte que os preconceitos que as cercam e dos modelos sociais que imaginavam que deveriam seguir.

\section{O filho de mil homens e a construção da família moderna.}

A noção de uma família ligada por laços fraternais é a principal contribuição que Valter Hugo Mãe traz no livro O filho de mil homens (2012), levantando uma discussão da condição pós-moderna na contemporaneidade. Este modelo familiar, caso fosse concebido há 50 anos, se assemelharia mais 
RESENHA: MẪE, Valter Hugo. 0 filho de mil homens. Săo Paulo: Cosac Naify, 2012. 0 FILHO DE MIL HOMENS E A CONSTRUÇÂO DA FAMÍLIA MODERNA

como um manicômio ${ }^{2}$ do que propriamente com uma família. Mãe, mexe em uma estrutura dita sagrada pela cristandade, incluindo no seu bojo pessoas que historicamente sempre pertenceram a um não lugar e, desta maneira, discute "as novas bases" do que comumente chamam-se de "família moderna".

A constituição desta família, para Mãe, não se dá de maneira simples, na medida em que os integrantes deste grupo primeiro passam por processos de exclusão social, são personagens que recebem o peso de não pertencer aos moldes pré-determinados da vila (ou do mundo), da qual, o conservadorismo e a desvalorização do que é diferente é implícito na personalidade de grande parte dos seus moradores. Não foi aleatório que Mãe a escolheu como cenário para compor sua narrativa. No romance, não explicita em que tempo e nem em que posição geográfica do globo a vila se encontra, pois, lugares como estes trazem em sua estrutura uma carga de sentidos que o leitor, independentemente da posição do globo, a reconhece. A vila, no romance, se estrutura como um personagem.

Este personagem representa o arcaico, o conservadorismo e a não aceitação da alteridade, na qual os rótulos, por serem diferentes, tornam-se um fardo que seus moradores devem carregar pelo resto da vida. Desta forma, para a vila, é impossível “o homem maricas” ser um cidadão aceitável socialmente, bem como a moça desvirginada reconstruir sua moral, o velho viúvo ser feliz; é inconcebível figuras diferentes do forjamento social machista deste espaço ter aceitação em sua estrutura, suas condições humanas devem permanecer estáticas e marginalizadas. A construção da felicidade destes "rebeldes" tem como primeiro passo o reconhecimento de que suas escolhas não são erros, “ $O$ Antônio sabia disso, que a vizinhança $o$ teria morto com alguma conviç̧ão de estar a fazer o que era certo. Com essa certeza, o Antônio abafava como pedra os sentimentos mais delicados, mascarando o desejo, colecionando numa mudez absoluta" (MÃE, 2012, p. 98)

A busca pela felicidade é uma característica de todos os personagens que fazem da família do Crisóstomo. Com isso, são obrigados a descobrir que é possível, que não são as aberrações, é necessário resgatar os traços de uma

${ }^{2}$ Espaço de exclusão do diferente 
humanidade esquecida na qual a vila os retirou. Como aponta Beuttermuller os "personagens são vítimas do que é considerado correto", dentro da sociedade conservadora da vila. As relações tradicionais não trazem a felicidade tanto desejada a essas personagens. (BEUTTENMULLER, 2012, p. 190-191).

Estes excluídos encontrarão a aceitação e integração ao lado do Crisóstomo, no qual seu entusiasmo é a chave para integração afetiva destas “aberrações", o seu amor, sua aceitação e, sobretudo, seu grande espírito de solidariedade é o que faz unir todos, amar sem esperar muito em troca, sem se importar com o que a vila irá pensar desta integração.

As escolhas das palavras no romance de Valter Hugo Mãe são precisas, ela fala de amor, sem cair em um romantismo barato, alicerça seu discurso na ideia de real, fala de esperança como algo possível, revelando que o processo da busca por uma comunidade pautada em solidariedade e aceitação das diferenças pode ser doloroso, mas possível. O livro O filho de mil homens, se insere dentro da condição pós-moderna, imprimindo uma mensagem de esperança, de que é possível ser feliz independentemente do que lhe ensinaram. Mostra que os excluídos sociais possuem chance maior de integração com união e, sobretudo, nos diz que para constituir uma família não é preciso se estar ligado por laços sanguíneos, e sim, por laços fraternais.

\section{Referências}

BEUTTENMULLER, Eric. Fraternidade de mil homens in: Revista Desassossego, 8 a ed. São Paulo, 2012.

MÃE, Valter Hugo. O filho de mil homens. São Paulo: Cosac Naify, 2012.

WOOD, James. Como funciona a ficção. Trad. Denise Bottmann. São Paulo: Cosac Naify, 2011.

Recebido em 30 de abril de 2017.

Aceito em 09 de junho de 2017. 